\title{
Combined effects of EPS and HRT enhanced biofouling on a submerged and hybrid PAC-MF membrane bioreactor
}

\section{Authors: Mohiuddin Md. Taimur Khan, Satoshi \\ Takizawa, Zbigniew Lewandowski, M. Habibur Rahman, Kazuhiro Komatsu, Sara E. Nelson, Futoshi Kurisu, Anne K. Camper, Hiroyuki Katayama, \& Shinichiro Ohgaki.}

NOTICE: this is the author's version of a work that was accepted for publication in Water Research. Changes resulting from the publishing process, such as peer review, editing, corrections, structural formatting, and other quality control mechanisms may not be reflected in this document. Changes may have been made to this work since it was submitted for publication. A definitive version was subsequently published in Water Research, 47, 2, February 2013. DOI\#10.1016/j.watres.2012.10.048.

Khan M,Takizawa S, Lewandowski Z, Rahman MH, Komatsu K, Nelson SE, Kurisu F, Camper AK, Katayama H, Ohgaki S, "Combined effects of EPS and HRT enhanced biofouling on a submerged and hybrid PAC-MF membrane bioreactor," Water Research February 2013 47(2):747-757. 


\section{Combined effects of EPS and HRT enhanced biofouling on} a submerged and hybrid PAC-MF membrane bioreactor

Mohiuddin Md. Taimur Khan ${ }^{a}, \mathbf{b}, *$, Satoshi Takizawa ${ }^{b}$, Zbigniew Lewandowski ${ }^{c}$, M. Habibur Rahman ${ }^{d}$, Kazuhiro Komatsu ${ }^{e}$ Sara E. Nelson $\mathbf{c}_{\text {, Futoshi Kurisu }}{ }^{b}$, Anne K. Camper ${ }^{c}$, Hiroyuki Katayama ${ }^{b}$, Shinichiro Ohgaki ${ }^{\mathrm{e}}$

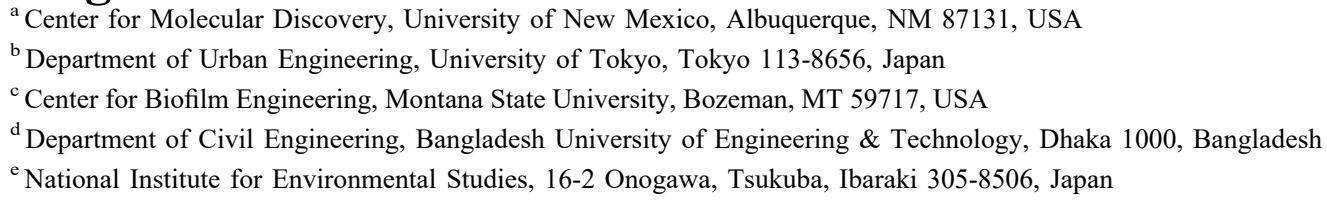

\section{A B S T R A C T}

The goal of this study was to quantify and demonstrate the dynamic effects of hydraulic retention time (HRT), organic carbon and various components of extracellular polymeric substances (EPS) produced by microorganisms on the performance of submersed hollow-fiber microfiltration (MF) membrane in a hybrid powdered activated carbon (PAC)-MF membrane bioreactor (MBR). The reactors were operated continuously for 45 days to treat surface (river) water before and after pretreatment using a biofiltration unit. The real-time levels of organic carbon and the major components of EPS including five different carbo-hydrates $(\mathrm{D}(\mathrm{b})$ glucose and $\mathrm{D}(\mathrm{p})$ mannose, D(p) galactose, N-acetyl-D-galactosamine and D-galactose, oligosaccharides and L(-) fucose), proteins, and polysaccharides were quantified in the influent water, foulants, and in the bulk phases of different reactors. The presence of PAC extended the filtration cycle and enhanced the organic carbon adsorption and removal more than two fold. Biological filtration improved the filtrate quality and decreased membrane fouling. However, HRT influenced the length of the filtration cycle and had less effect on organic carbon and EPS component removal and/or biodegradation. The abun-dance of carbohydrates in the foulants on MF surfaces was more than 40 times higher than in the bulk phase, which demonstrates that the accumulation of carbohydrates on membrane surfaces contributed to the increase in transmembrane pressure significantly and PAC was not a potential adsorbent of carbohydrates. The abundance of N-acetyl-D-galactosamine and D-galactose was the highest in the foulants on membranes receiving biofilter-treated river water. Most of the biological fouling compounds were produced inside the reactors due to biodegradation. PAC inside the reactor enhanced the biodegra-dation of polysaccharides up to $97 \%$ and that of proteins by more than $95 \%$. This real-time extensive and novel study demonstrates that the PAC-MF hybrid MBR is a sustainable technology for treating river water. 


\section{Introduction}

In the past decades, microfiltration (MF) has emerged as one of the most reliable, cost-effective and sustainable unit processes for surface water treatment separating macromolecules, bacteria and discrete particles (Lebeau et al., 1998; Khan et al., 2001, 2011; Fabris et al., 2007). In this process, biofouling has been identified as the key factor affecting long-term MF membrane separation processes and worsening overall plant performance. The biofouling process initiated by bacterial attachment to the surface of a membrane gradually reduces its flux and may lead to structural failure of the membrane (Khan et al., 2010). Bacteria imbedded in extracellular polymeric substances (EPS) form a highly hydrated gel layer on the MF membrane surface that affects its performance in several ways (Jarusutthirak and Amy, 2006; Fonseca et al., 2007).

EPS are large molecular weight compounds excreted by bacteria, such as polysaccharides, proteins, lipids and DNA (Barker and Stuckey, 1999; Wingender et al., 1999; Barker et al., 2000; Ye et al., 2005). These substances affect the development of biofouling deposits on membranes and alter physicochemical characteristics of the membrane such as electrical charge, hydrophobicity, and chemical properties (Nagaoka et al., 2000; Gómez-Suárez et al., 2002; Mikkelsen and Keiding, 2002; Khan et al., 2010, 2011). Moreover, polysaccharide and metal-ion specific interactions have a major effect on the mechanical stability of biofoulants (Turakhia and Characklis, 1989). The components of EPS also create scaffolds with physical characteristics and interconnected pore structures that promote membrane flux decline and further cell attachment, proliferation and differentiation (Chen and Ma, 2004; Wotton, 2004; Park et al., 2005). Although the initial adhesion mechanism is still not entirely clear, it is known that over time the bonding strength of the EPS to the membrane increases, mostly because of the flexibility of the gel layer and the cross-linking of the EPS on the membrane surface (Tansel et al., 2006). In general, when the EPS concentration increases, cell adhesion is enhanced by polymeric interactions (Tsuneda et al., 2003).

To counteract the effects of membrane fouling, maintenance by periodic chemical cleaning or membrane replacement needs to be carried out which will inevitably accrue higher costs of the MBR process (Ng et al., 2006). Therefore, operational adjustments that can reduce the effects of fouling will increase productivity of membrane processes. The process of adsorption using powdered activated carbon (PAC) can be hybridized with the MF membranes to remove organic compounds (Basar et al., 2004; Thiruvenkatachari et al., 2006), disinfection byproducts (Khan et al., 2009), 17 -estradiol (an endocrine disrupting compound) (Lee et al., 2009), microorganisms like Norovirus (27-40 $\mathrm{nm}$ in diameter) (Oh et al., 2007), atrazine (Jia et al., 2009), and other substances. In our previous studies (Khan et al., 2001; Kim et al., 2005) on PAC-MF systems for surface water treatment, in which the PAC dose was varied from 0 to $50 \mathrm{~g} / \mathrm{L}$ of the reactor, we observed that at $40 \mathrm{~g}$ of $\mathrm{PAC} / \mathrm{L}$ of the reactor, the membrane fouling frequency was the lowest. Experimental results from wastewater treatment showed that PAC dosing resulted in lower concentrations of soluble EPS and colloidal total organic carbon (TOC) in the PAC-MBR sludge (Yang et al., 2010). Such a hybrid process improves membrane performance and extends the filtration periods, likely because the presence of PAC interferes with the process of fouling. Due to the presence of PAC, the total cost for membrane maintenance could be reduced by $25 \%$ in a PAC-MBR system treating municipal wastewater (Kim et al., 2006). To further improve this process, better and important understandings of the differences in biofouling between MF filtration with and without PAC are needed. One of the main factors affecting biofouling, the fate of EPS in hybrid MF MBRs, is not well understood and explored. Furthermore, biofiltration pretreatment of surface water also improves PAC-MF system performance (Kim et al., 2005; Khan et al., 2009), but its role in EPS removal from surface water has not been demonstrated yet.

It was further demonstrated that a decrease in hydraulic retention time (HRT) enhanced growth of biomass and accumulation of soluble microbial products (SMP), which accelerated membrane fouling rate (Huang et al., 2011). Other work showed that low HRT caused excessive growth of filamentous bacteria which resulted in high EPS concentration, high solid concentration and sludge viscosity (Meng et al., 2007). We hypothesized that PAC particles inside a MF membrane reactor would adsorb and enhance the biodegradation of EPS regardless of whether the EPS was from the influent river water or produced inside the reactor as well as reduce the membrane cleaning frequency. The presence of PAC would interfere with the biofouling process and increase the filtration period at higher HRT; however, this presence and pretreatment of river water would not affect the number of filtration cycles for the membrane modules operated at reduced HRT. In this study, we monitored the concentrations of the major EPS components: carbohydrates, proteins and polysaccharides, and their effects on MF membrane fouling in the presence and absence of PAC and biofiltration pretreatment of surface water at two different HRT.

Bench-scale experiments on a PAC-MF MBRs were carried out using settled surface water (Tama River, Tokyo, Japan) either before or after treatment by a biofilter system, depending on the experimental protocol. More than $80 \%$ of the total flow of this river consists of the treated effluent from wastewater treatment plants located upstream. As a result, dissolved organic matter (DOM) and other biodegradable contaminants in the river water exist at much higher concentrations than in typical surface waters. Implementing the PAC-MF MBR process may improve the quality of the treated water considerably. The objectives of this study were to: (1) quantify the effect of HRT in the presence and absence of PAC and biofiltration pretreatment of surface water on MF membrane performance, and (2) quantify the kinetics of realtime adsorption and/or biodegradation of EPS components and their effects on MF membrane fouling at varied operational conditions in the PAC-MF MBR.

\section{Experimental section}

\subsection{Site location}

The Tokyo Metropolitan Authority has a water treatment plant to treat water from the Tama River, which is located in 
the southwest region of Tokyo, around $15 \mathrm{~km}$ from the main city. The treated water is supplied only for industrial use. The bench-scale experiments on the submerged PAC-MF MBRs were performed in this treatment plant. River water was pumped from the intake point to a series of primary and secondary sedimentation ponds. A stream of water taken from the secondary ponds was split into four streams; three of these streams were used directly as feed into three reactors, while the fourth stream was directed after pretreatment by a biofilter into two reactors. The reactor set-up used in this study is shown schematically in Fig. 1.

\subsection{Experimental design and operational conditions of} the reactors

Five bench-scale reactors (Table 1) were operated continuously for 45 days. Each reactor consisted of a hollow-fiber MF membrane module operated in suction mode to maintain constant flux. The biofilter consisted of a column packed with polypropylene pellets with a length of $5 \mathrm{~mm}$, an inner diameter of $3 \mathrm{~mm}$ and an outer diameter of $4 \mathrm{~mm}$. The filtration velocity and retention time of this biofilter were $320 \mathrm{~m} / \mathrm{d}$ and $\sim 10 \mathrm{~min}$, respectively. Discharges from the biofilter and raw water were stored separately in two 100-L reservoirs and stirred continuously prior to being fed into the reactors. The polyethylene hydrophilic membrane used in this study was made by Mitsubishi Rayon Co. Ltd., Japan. The membrane properties, and reactor configurations are described elsewhere (Khan et al., 2009, 2011). Briefly, the nominal pore size was $0.1 \mu \mathrm{m}$, and the outer and inner diameters were $0.41 \mathrm{~mm}$ and $0.27 \mathrm{~mm}$, respectively. The reactors were made of $5-\mathrm{mm}$ thick polyvinyl chloride plates, and each had an effective volume of $5 \mathrm{~L}$. The membrane modules were cleaned with
Milli-Q water when received and soaked in fresh Milli-Q water prior to use. The experiment was carried out under ambient conditions $\left(17-28^{\circ} \mathrm{C}\right)$.

Reactors $\mathrm{R} 1-\mathrm{R} 3$ received settled river water, while reactors $\mathrm{R} 4$ and $\mathrm{R} 5$ received the biofilter system effluent. PAC (coconut shell origin, JWWA K 113-1985, Shirosagi-C, Takeda Chemical Co., Japan) was used as received and the dose was $40 \mathrm{~g}$ of PAC/ $\mathrm{L}$ of the reactor was added into reactors R2-R5 at the beginning of operation. Reactor R1 was operated without PAC as a control. No modifications were made to the method of operation, and no additional PAC was added.

While maintaining the same filtration flux, the number of membrane fibers in the reactors operated at lower HRT (1.2 h) was twice higher (640 fibers) than that of those operated at higher HRT. It is not possible to calculate the effective membrane surface areas during each suction and backwashing cycle; therefore, it was assumed that the entire membrane surface area was effectively used in the process. Aeration (see Fig. 1) was maintained underneath the fiber module to disturb cake formation on the membrane surface and to prevent rapid flux decline of the submerged membrane modules. The airflow rate underneath the module that contained a higher number (640 fibers) of membrane fibers (R3 and R5) was twice than that of the other modules with lower numbers (320 fibers) of fibers (R1, R2 and R4) (see Table 1).

Level sensors were used to ensure a constant reactor volume, and suction through the membrane module maintained a constant flow rate. All systems were equipped with a backwash mechanism, providing 2 min of backwash after every $20 \mathrm{~min}$ of filtration. Fouled membranes were backwashed with the stored filtrate (Fig. 1). The backwash-water reservoirs were cleaned once a week and refilled with fresh filtrate, and the backwashing flux was twice as high as the

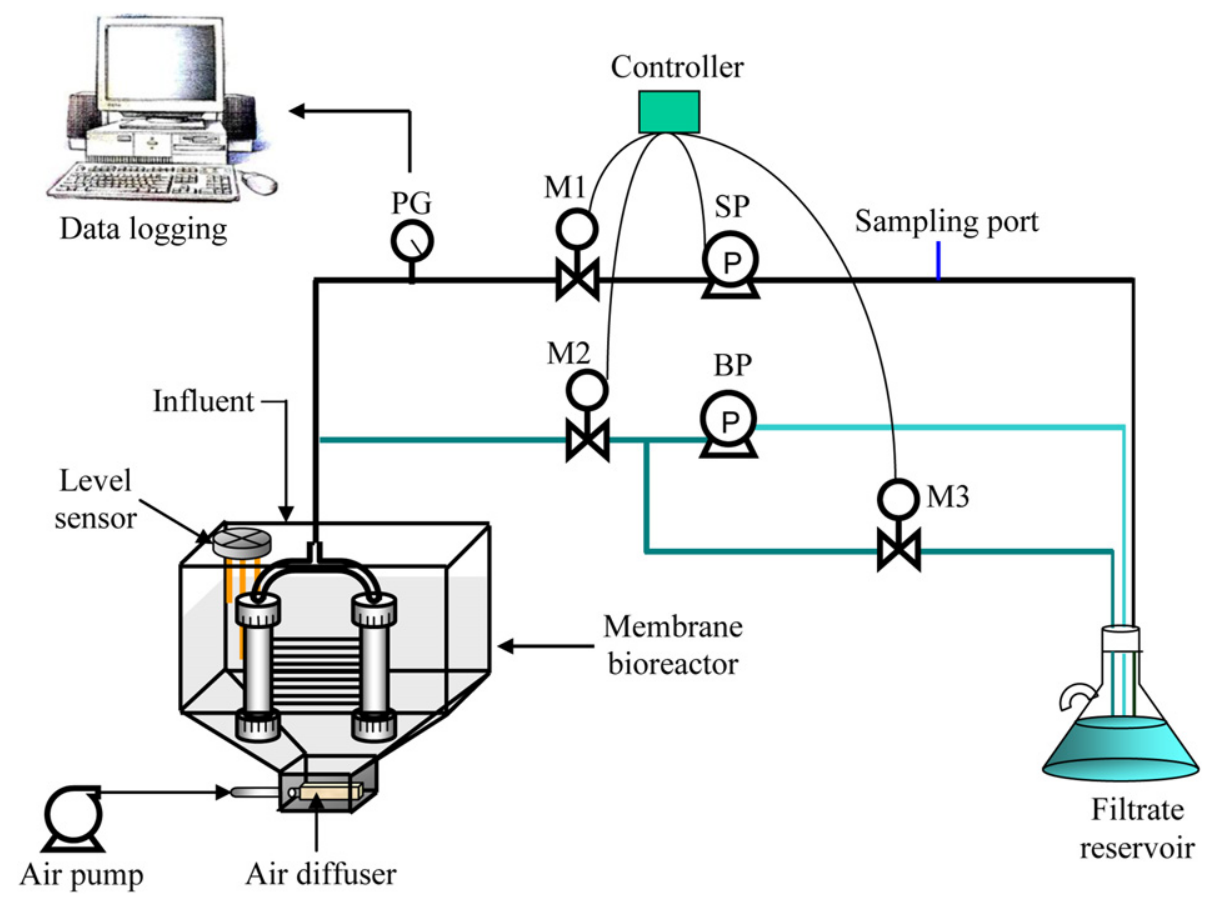

Fig. 1 - Schematic diagram of a single PAC-MF unit. Here, PG is the pressure gauge (connected with computer), M1 the electric valve for retardation of water during backwash, M2 the electric valve for backwash, M3 the electric valve for water circulation, SP the suction pump (connected to controller) and BP the backwash pump (not connected to controller). 
Table 1 - Operating conditions of various reactors during 45 days of filtration experiment. The membrane filtration flux was $20.8 \mathrm{~L} / \mathrm{m}^{2} / \mathrm{h}$ for all reactors.

\begin{tabular}{|c|c|c|c|c|c|c|}
\hline Reactor & $\begin{array}{c}\text { PAC } \\
\text { (g/L of the reactor) }\end{array}$ & Influents & $\begin{array}{l}\text { Duration of filtration } \\
\text { and backwashing } \\
\text { time (min) }\end{array}$ & $\begin{array}{l}\text { Aeration } \\
\left(\mathrm{L} / \mathrm{m}^{3} / \mathrm{min}\right)\end{array}$ & $\begin{array}{l}\mathrm{HRT} \\
\text { (h) }\end{array}$ & $\begin{array}{l}\text { Operational } \\
\text { objective }\end{array}$ \\
\hline R1 & 0 & River water & 20 and 2 & 1000 & 2.4 & Control (no PAC) \\
\hline R2 & 40 & River water & 20 and 2 & 1000 & 2.4 & $\begin{array}{l}\text { Standard operation } \\
\text { with PAC and } \\
\text { river water }\end{array}$ \\
\hline R3 & 40 & River water & 20 and 2 & 2000 & 1.2 & $\begin{array}{l}\text { Effect of HRT on } \\
\text { standard operation }\end{array}$ \\
\hline R4 & 40 & Biofiltered water & 20 and 2 & 1000 & 2.4 & $\begin{array}{l}\text { Effect of pretreatment } \\
\text { of river water on } \\
\text { standard operation }\end{array}$ \\
\hline R5 & 40 & Biofiltered water & 20 and 2 & 2000 & 1.2 & $\begin{array}{l}\text { Effect of HRT and } \\
\text { pretreatment of river } \\
\text { water on standard } \\
\text { operation }\end{array}$ \\
\hline
\end{tabular}

filtration flux. Transmembrane pressure (TMP) and backwashing pressure (BWP) were automatically recorded using a data logger. Once TMP values reached to $50 \mathrm{kPa}(0.5 \mathrm{bar})$, the fouled membrane modules were removed from the reactors and washed with the Milli-Q water using a soft brush to remove the foulants from the membrane surfaces. Pure water flux was measured after membrane cleaning.

\subsection{Analytical techniques}

\subsubsection{Measurement of total organic carbon (TOC) and} dissolved organic carbon (DOC)

To measure the TOC and DOC, the influents and effluents of each reactor were homogenized (Branson Sonifier 450, Yamato, Japan) for 10 min using specific protocols developed in our previous study (Khan et al., 2009). The homogenized samples were filtered through $0.45 \mu \mathrm{m}$ pore size polyvinylidene fluoride (PVDF, Millipore, USA) filters for DOC measurement. A total organic carbon analyzer (TOC-5000A, Shimadzu Co., Osaka, Japan) was used to measure TOC and DOC of the samples.

\subsubsection{Extraction of EPS from reactor and membrane samples} EPS extracted from the bulk liquid and from the foulants on membrane surfaces were stained with lectins specific to particular carbohydrate moieties. The EPS extraction protocol used here is modified from Zhang et al. (1999). They extracted EPS in various ways from different activated sludge samples and proposed a method for extracting EPS based on the highest recovery of carbohydrates, proteins and DNA. We introduced a new method of EPS extraction from samples with low to very high concentration of inert particles, especially PAC. Several trials were done to obtain the maximum recovery of the target materials. To extract the EPS, the samples (foulants on the membrane surfaces, bulk samples in reactors and influents to the reactors) were passed through $0.45 \mu \mathrm{m}$ pore size PVDF membrane (Millipore, USA) separately and then, $10 \mathrm{~g}$ of retained sediment on this membrane were placed in a centrifuge tube and suspended in $25 \mathrm{ml}$ of Milli-Q water, shaken and then centrifuged at $3500 \mathrm{rpm}$ for $10 \mathrm{~min}$. The supernatant was decanted and set aside. The pellet remaining in the centrifuge tube was re-suspended in $25 \mathrm{ml}$ of $8.5 \% \mathrm{NaCl}$ and $0.22 \%$ formaldehyde. The mixture was vortexed at high speed for $1 \mathrm{~min}$ to recover the capsule-bound material. The previously retained supernatant was then added, and $15 \mathrm{ml}$ of this mixture (now $50 \mathrm{ml}$ plus original sediment sample) was centrifuged at $12,000 \mathrm{rpm}$ for $30 \mathrm{~min}$. The supernatant was collected and filtered through a $0.2 \mu \mathrm{m}$ cellulose acetate filter (Millipore, USA). Activated sludge (2 g) sample from the Shinagawa Wastewater Treatment Plant (Japan) was used as a positive control and EPS from this sludge sample were extracted using the above protocol.

\subsubsection{Target lectins}

The lectins used in this study were: $(1) \mathrm{D}(+)$ glucose and $\mathrm{D}(+)$ mannose (fluorescein isothiocyanate (FITC) fluorochrome); (2) $\mathrm{D}(+)$ galactose (FITC fluorochrome); (3) N-acetyl-D-galactosamine and D-galactose (FITC fluorochrome); (4) L(-) fucose (tetramethylrhodamine isothiocyanate (TRITC) fluorochrome); and (5) oligosaccharides (TRITC fluorochrome) (Sigma-Aldrich Co., USA). Each lectin corresponds to a specific carbohydrate. The lectins used in this study were selected/ considered after detailed investigations (data not shown) based on the abundance and availability of the corresponding carbohydrates in the surface water sources and wastewater systems. The lectin powders were diluted to $0.2 \%$ with $1 \mathrm{~N}$ polyphosphate buffer (PBS) solution (8 g/L NaCl, $1.1 \mathrm{~g} / \mathrm{L}$ $\mathrm{Na}_{2} \mathrm{HPO}_{4}-$ anhydrous, $0.2 \mathrm{~g} / \mathrm{L} \mathrm{KCl}$, and $0.2 \mathrm{~g} / \mathrm{L} \mathrm{KH}_{2} \mathrm{PO}_{4}$ ). The dilute lectins were stored at $-20{ }^{\circ} \mathrm{C}$ and covered with aluminum foil to protect them from light exposure.

2.3.4. Labeling of different lectins with extracted EPS samples $5-\mu l$ of the extracted EPS sample was placed drop-wise on a glass slide and oven-dried at $90-95{ }^{\circ} \mathrm{C}$ for $5 \mathrm{~min}$. A labeled lectin solution $(10 \mu \mathrm{l})$ was then placed on top of the dried droplet at room temperature. The labeled lectin was allowed to react with the corresponding carbohydrate for $10 \mathrm{~min}$ in the dark, after which the slide was washed very gently with Milli$Q$ water and then shaken until air-dried. One drop of SLOW FADE (Molecular Probe, USA) was placed on top of the dried 
sample, and a cover slip was placed on top of it. Each lectin labeled sample was observed under an epifluorescence microscope (Nikon, Eclipse E 800, Japan) using a 100× objective. Several images (8-10 images) were captured for each sample labeled with different lectins. FITC was excited at $494 \mathrm{~nm}$, and TRITC was excited at $550 \mathrm{~nm}$. The gain and offset for each photomultiplier were adjusted to optimize lectin detection. Stored images were analyzed in Photoshop (version 5.0) software to compute the light intensity (green from FITC fluorochrome and red from TRITC fluorochrome), and a mean value of light intensity for each lectin was estimated and averaged.

\subsubsection{Protein and polysaccharides measurements}

The extracted EPS from different samples (foulants on the membrane surfaces, bulk samples in reactors and influents to the reactors) were used in the protein and polysaccharide assays. The total protein was further extracted from EPS samples using the Bicinchoninic Acid (BCA) protein assay reagent kit (Pierce, BCA protein assay reagent kit, 23225). Protein standards were prepared in the range of $0-50 \mathrm{mg} / \mathrm{L}$ with bovine serum albumin (BSA) from $2 \mathrm{mg} / \mathrm{ml}$ of albumin supplied with this kit. The enhanced protocol (Pierce, instructions) was followed. The absorbance of the cooled samples at $562 \mathrm{~nm}$ was compared to the standard curve. The polysaccharide in the extracted EPS was measured using the phenol-sulfuric acid method. The absorbance of cooled samples at $490 \mathrm{~nm}$ was compared to the standard curve. The spectrophotometer U-2010 (Hitachi Co., Japan) was used to measure the absorbance of the samples.

\section{Results and discussion}

\subsection{TMP of membrane modules and effects of HRT on membrane fouling}

The transmembrane pressure (TMP) of membrane modules inside all reactors increased with time (Fig. 2). In the case of reactors operated at higher HRT $(2.4 \mathrm{~h})$, the system treating raw water without PAC (reactor R1) accumulated TMP more rapidly than the other two systems (reactors $R 2$ and $R 4$ ). The number of cleaning cycles associated with membrane fouling during the filtration period (45 days) was the highest (4 cleaning cycles) in reactor R1; however, that was lowered to thrice in the presence of PAC in reactor R2, which was further reduced to twice in the presence of PAC and biofilter-treated raw water in reactor R4. However, the other reactors (reactors R3 and R5) operated at lower (1.2 h) HRT and in the presence of PAC had rapid TMP increase and required more cleaning cycles (total of 4).

Interestingly, reactors R3 and R5 were operated in the presence of PAC and the influents to the reactors were different (settled river water without and with biofilter-treated water, respectively). The decrease of HRT increased the frequency of membrane cleaning in both reactors.

Prior work with PAC and microfiltration (Khan et al., 2011) showed that cake and gel layer formation are the primary mechanisms of membrane fouling: the adsorbed and attached materials on the PAC were responsible for the loss in

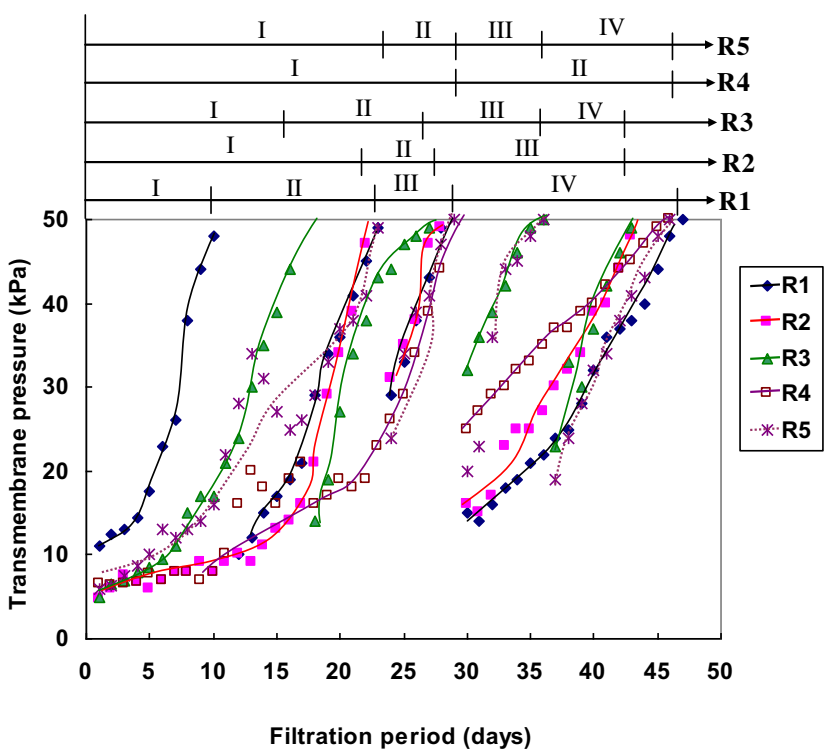

Fig. 2 - Transmembrane pressure (TMP) record for the MF membrane modules in the reactors. One $\mathrm{kPa}=0.01$ bar. The Roman numerals at the top of the figure indicate the number of cleanings for each module. The membranes inside R1, R3 and R5 fouled 4 times; however, those inside R2 and R4 fouled thrice and twice, respectively. The HRT of reactors $R 1, R 2$ and $R 4$ was kept at $2.4 \mathrm{~h}$ and that of reactors $\mathrm{R} 3$ and $\mathrm{R} 5$ was kept at $1.2 \mathrm{~h}$.

performance. The addition of PAC reduced the membrane resistance to filtration, which was reduced further in the presence of a biofilter as a pretreatment (Khan et al., 2011). However, in present experiment, a thick cake layer was not formed on the outer surface of any of the fouled membranes. During physical cleaning, very thin (0.4-0.9 mm thick) foulant layers were formed on the membrane surfaces where aeration could reach and thicker cake ( $3.5-5 \mathrm{~mm}$ thick) was observed to have accumulated primarily between membrane fibers at the ends of the fibers, where aeration could not reach. Due to the turbulence produced by aeration, the attached foulants to the membrane surfaces were scoured continuously back into the bulk solution of the reactors and the mass transport through the membrane surfaces were also enhanced (Chu and Li, 2005; Sun et al., 2008). It is likely, then, that aeration significantly contributed to the removal of cake fouling in this system.

The influents to reactors R3 and R5 were different; however, the HRT, filtration-backwashing cycle and PAC loading conditions were similar in both reactors (Table 1). Therefore, the reduction of HRT affected the membrane fouling rate even though the aeration rate was doubled in these two reactors compared to other reactors (R1, R2 and R4). We did not operate a control reactor (raw water and no PAC) at lower HRT in this study; therefore, it is not possible to compare the effect of aeration on membrane fouling at higher and lower HRT. However, in previous reports (Ueda et al., 1997; Khan et al., 2009), it was observed that aeration significantly reduced the fouling frequency of the membrane modules when they were operated at similar HRT. 
Based on our pervious study (Khan et al., 2009) and microscopic observation, we noticed that during filtration, suspended particles (including PAC in reactors R2 through R5) inside the reactors accumulated on the membrane surfaces and then were dispersed inside the reactors during backwashing; i.e. no irreversible fouling effect. However, in this study, we noticed significant irreversible fouling effects on the membranes operated at lower HRT (reactors R3 and R5). After physical cleaning of the membrane modules inside reactors, the TMP started from higher values in the filtration cycle than that in the previous cycle of operation especially R3 and R5. This observation suggests that HRT is one of the most important parameters during system (PAC-MF MBR) design.

This irreversible fouling effect also correlates with the backwashing pressure (BWP) record of the membrane modules (Fig. 3). The reactors were operated at a constant flux $\left(20.8 \mathrm{~L} / \mathrm{m}^{2} / \mathrm{h}\right)$. During suction, the foulants were attached on the surface of the membrane and backwashing removed some of the foulants from the membrane pores and their surrounding areas. However, the amounts of the foulants removed during backwashing were less than the accumulation during suction; therefore, TMP increased (Fig. 2) during each filtration cycle and finally cleaning of membranes was required. The BWP of membrane modules in reactors $\mathrm{R} 3$ and R5 operated at lower HRT was the highest ( $>40 \mathrm{kPa}$ ) compared to others at the end of each filtration cycle. In this study, the backwashing flux in all reactors was kept similar to the filtration flux $\left(20.8 \mathrm{~L} / \mathrm{m}^{2} / \mathrm{h}\right)$. Due to reduced HRT, the BWP of the modules inside these two reactors was higher than that in other reactors operated at higher HRT, even though the aeration rate was doubled inside the reactors $\mathrm{R} 3$ and $\mathrm{R} 5$.

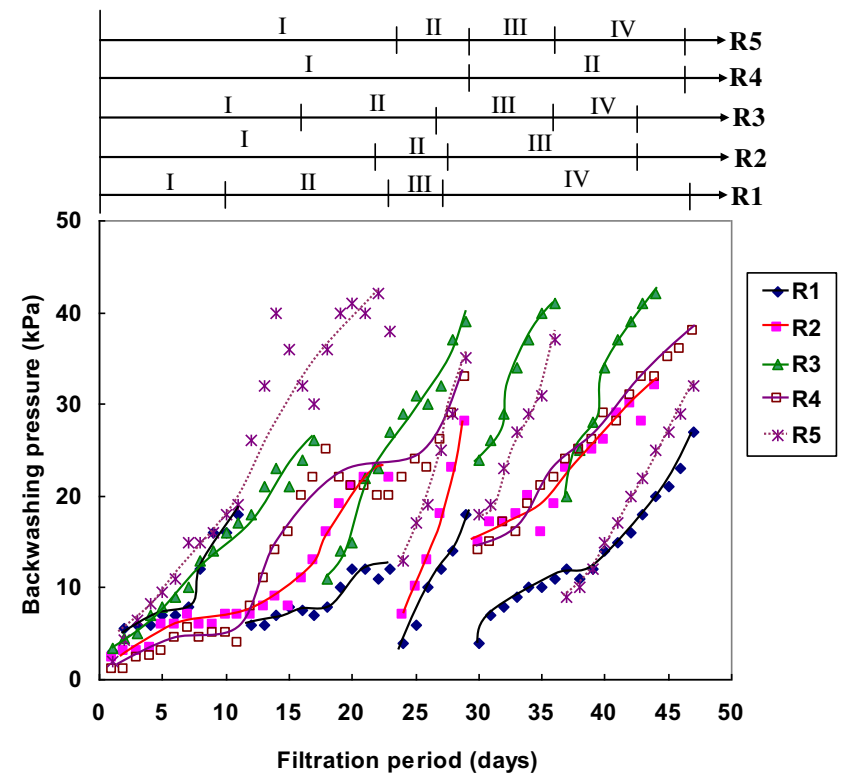

Fig. 3 - Backwashing pressure (BWP) record for the MF membrane modules in the reactors. One $\mathrm{kPa}=0.01 \mathrm{bar}$. The Roman numerals at the top of the figure indicate the number of cleanings for each module. The membranes inside R1, R3 and R5 fouled 4 times; however, those inside R2 and R4 fouled thrice and twice, respectively. The HRT of reactors $R 1, R 2$ and $R 4$ was kept at $2.4 \mathrm{~h}$ and that of reactors $\mathrm{R} 3$ and $\mathrm{R} 5$ was kept at $1.2 \mathrm{~h}$.
Interestingly, in our previous study (Khan et al., 2011), we doubled the backwashing flux of the modules and irreversible fouling effects were negligible.

\subsection{The effect of HRT on organic carbon removal}

The average TOC concentrations were similar to those in the influents of raw and biofiltered water $(2.35 \pm 0.25 \mathrm{mg} / \mathrm{L}$ in and $2.10 \pm 0.38 \mathrm{mg} / \mathrm{L}$, respectively). During this study the biofiltration unit (used for the pretreatment of raw water) removed only $\sim 10 \%$ of the organic carbon. In our previous study (Khan et al., 2011) we demonstrated that the biofiltration unit removed a significant amount $(\sim 80 \%)$ of biomass and inert solids from the raw water and the organic carbon was adsorbed by the biomass in the biofilter and finally biodegraded. Furthermore, the organic matter sloughed from the biofiltration unit could potentially increase the organic carbon concentration in its effluent.

The removal efficiency of TOC in reactor R1 (system operated at higher HRT and treated raw water without PAC) was the lowest ( 30\%) (Fig. 4). However, other reactors operated at either higher or lower HRT that received different influents (R2 and $\mathrm{R} 3$ received raw water and $\mathrm{R} 4$ and $\mathrm{R} 5$ received biofiltered water) with the addition of PAC showed $>66 \%$ TOC removal. No significant difference in TOC removal between these reactors (R2-R5) was observed. It appears that TOC removal efficiency is related to the presence of PAC and this efficiency was not affected by the HRT and type of source water (influents to the reactors). According to the TOC mass balance, the total amounts of organic carbon that entered into the reactors receiving raw water (reactors $\mathrm{R} 1-\mathrm{R} 3$ ) and biofiltered water (reactors R4 and R5) were $2.64 \mathrm{~g}$ and $2.36 \mathrm{~g}$, respectively, during the filtration period.

The reactors operated with PAC could remove or retain $>66-71 \%$ of the TOC that entered in the system; however, $<30 \%$ of the TOC was removed by the reactor without PAC (R1) (Fig. 4). The remaining TOC in R1 was either degraded inside the reactor (probably biodegraded by the suspended biomass and/or attached biofilm on the membrane surfaces) and/or

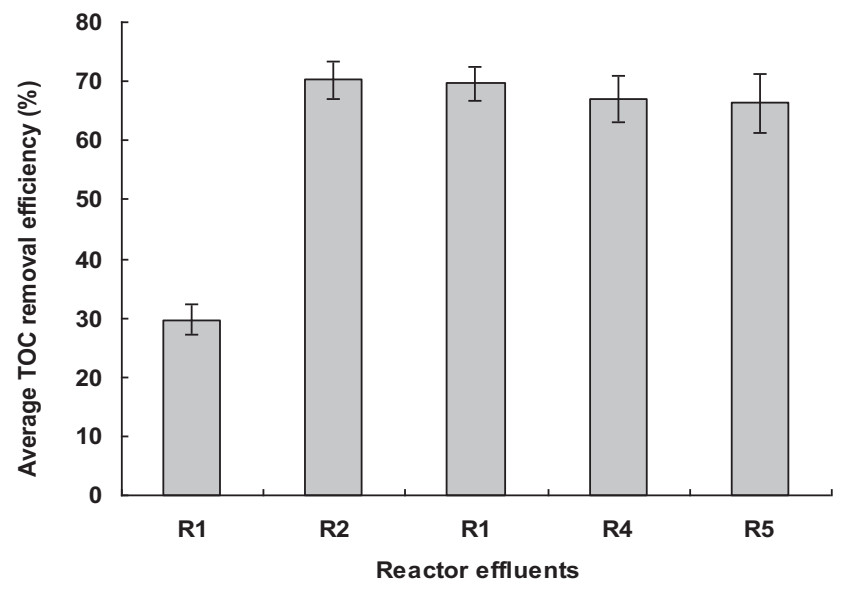

Fig. 4 - Removal efficiency of total organic carbon (TOC) by the membrane reactors operated with and without PAC at different HRT. The HRT of reactors R1, R2 and R4 was kept at $2.4 \mathrm{~h}$ and that of reactors $\mathrm{R} 3$ and $\mathrm{R} 5$ was kept at $1.2 \mathrm{~h}$. 
remained as adsorbed phases and therefore could be accumulated over time. However, the remaining $>66 \%$ of TOC inside the reactors operated with PAC (R2-R5) was mostly adsorbed on the PAC and then remained in as the attached phase or was degraded by the microorganisms on the PAC or in the bulk phase (Vigneswaran et al., 2006). The DOC levels inside all reactors containing PAC were similar and did not vary much during the filtration period (see Supplementary Fig. 1). However, in the reactor without PAC (R1), the DOC level increased with time of filtration and this level was higher ( thrice) than that in other reactors. We observed significant differences in DOC level between the reactors operated with and without PAC. This clearly indicates that PAC not only adsorbed but also maintained the level of TOC inside the system; however, the PAC has finite adsorption capacity (Khan et al., 2009).

\subsection{Influence of carbohydrates on membrane performance}

Lectins are proteins/glycoproteins with at least one noncatalytic domain binding reversibly to specific monosaccharides or oligosaccharides without having any enzymatic activity toward their carbohydrate ligands (Goldstein et al., 1980; Kocourek and Horejsí, 1981). By binding to carbohydrate moieties on the cell surface, lectins participate in a range of cellular processes without changing the properties of the carbohydrates involved (Lam and Ng, 2011; da Nóbrega et al., 2012). The lectins used in this study are from plant proteins. Fig. 5 shows the representative abundance of different fluorescent lectins binding with the sample from reactor R1. The abundance of $\mathrm{N}$-acetyl-D-galactosamine and Dgalactose was the highest and that of $\mathrm{D}(+)$ galactose was the lowest. In general, the abundance of other fluorescent lectins is also the highest in the reactor operated without PAC, (R1, data not shown) and this may indicate that the presence of PAC changes the carbohydrate composition due to different biochemical reactions/interaction in the presence of microorganisms (Jang et al., 2007).
Similar images were obtained for the other lectins and their corresponding mean values of light intensity were calculated. Because each fluorescent lectin has different light scattering and absorption properties, it was not possible to compare intensities among lectins in a manner that quantifies the carbohydrate content. Comparisons were performed only among samples labeled with the same lectin. Fig. 6 illustrates the average light intensity of fluorescent $\mathrm{N}$-acetyl-D-galactosamine and D-galactose in the foulants on the all membranes surfaces at the end of each fouling cycle and activated sludge (positive control sample). The level of this lectin increased with time inside reactor R5; however, this level did not increase in reactor $\mathrm{R} 4$. Both were operated with biofiltered water in the presence of PAC, but the HRT was different. Therefore, the shorter HRT (reactor R5) enhanced the accumulation of carbohydrates detected by this specific lectin and potentially contributed to more fouling of the membrane module. In membrane foulant samples at the end of each fouling cycle for other four lectins, the highest light intensities were also observed in reactor R1 (raw water without PAC) (Supplementary Table 1).

Except for $\mathrm{L}(-)$ fucose, the fluorescent intensities among the four lectins in the membrane foulants of reactor R1 were equal to or greater than those of the activated sludge (positive control) sample. This observation corroborates with the TOC adsorption data. The abundance of $\mathrm{D}(+)$ glucose and $\mathrm{D}(+)$ mannose was higher in the reactors that received biofiltered water (R4 and R5). In the reactors ( $R 2$ and R4) operated at higher HRT and with PAC, the levels of lectins (fluorescent intensities) were lower, but still higher than those in the reactors were operated at lower HRT (R3 and R5) even in the presence of PAC.

The average mean values of fluorescent light intensities of lectins that detect all carbohydrates in both raw and biofiltered water were less than 1.0; however, those in the foulants on membranes were 40-60 times higher than the samples in bulk phase (Supplementary Table 2) of the reactors, which supports the idea that the accumulation of carbohydrates on membrane surfaces contributed to flux
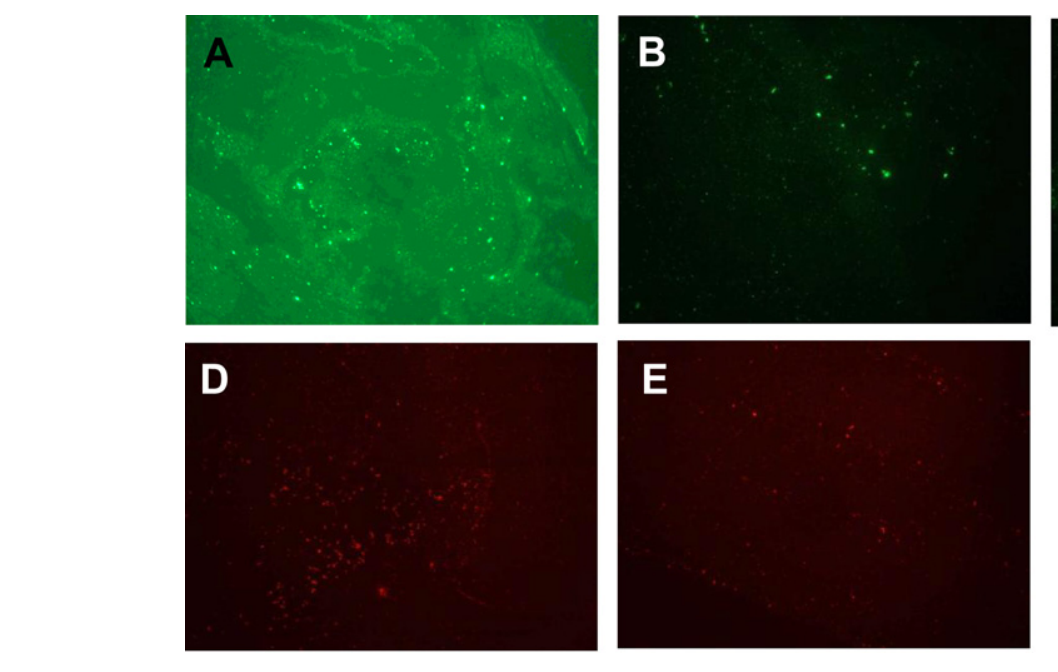

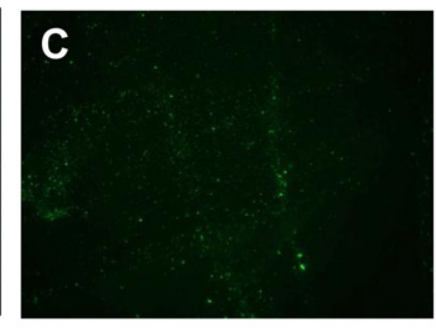

Fig. 5 - Abundance of $(A) D(+)$ glucose and $D(+)$ mannose; (B) $D(+)$ galactose; (C) N-acetyl-D-galactosamine and $D$-galactose; (D) $\mathrm{L}(-)$ fucose; and (E) Oligosaccharides in the bulk phase of R1 (raw without PAC) on Day-10, the first fouling day of MF membrane module in reactor $\mathrm{R} 1$. 


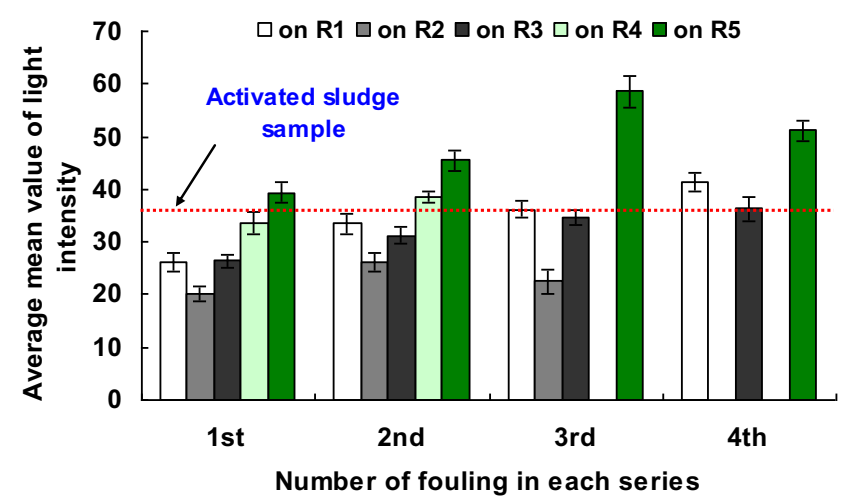

Fig. 6 - Average mean values of light intensity of N-acetyl$\mathrm{D}$-galactosamine and $\mathrm{D}$-galactose in the foulants on membrane surfaces at the end of each filtration cycle. Error bars show the \pm standard error of the mean (SEM) was determined in triplicate. The membranes inside R1, R3 and R5 fouled 4 times; however, those inside R2 and R4 fouled thrice and twice, respectively. The dotted line represents the average mean values of light intensity of $\mathrm{N}$-acetyl-Dgalactosamine and $\mathrm{D}$-galactose in activated sludge sample $(35.13 \pm 3.65)$ as positive control.

decline and TMP increase. Lee et al. (2001) reported that despite the similar characteristics of soluble fractions in the reactors, the membrane fouling rate due to attached growth system was about 7 times higher than that of the suspended growth system. This corroborates the effect of carbohydrate accumulation on membrane performance.

The fluorescent light intensity levels of all lectins in the bulk phases increased with time. However, the differences of the fluorescent light intensity levels of these lectins in the bulk phase and in the foulants of membranes indicate that due to the biological activities inside the bioreactor, carbohydrates not only accumulated, but also were produced inside the systems. Doumèche et al. (2007) observed that fluorescent lectins were conjugated or located in both microcolonies and microbial cells, which indicates a high degree of spatial organization and heterogeneity of carbohydrates within the foulants. The TMP records (Fig. 2) indicate that the presence of PAC and BF pretreatment of the surface water decreased TMP during filtration at higher HRT. Therefore, we hypothesize that the long chain carbohydrates act as bonding agents among the particles and other foreign dissolved and suspended matters, which causes stronger bridges among the available membrane surfaces and also the particles, resulting in increased TMP (Flemming, 1993). The amount of PAC in the bulk phase was much higher than that in the foulants on the membrane (Khan et al., 2011) and 40-60 times higher fluorescent light intensities of lectins in the foulants on membrane surfaces than that in bulk phase indicates that PAC is not a good adsorbent for carbohydrate. Once the PAC and other particles were attached to the membrane surface forming foulant layers, higher level of carbohydrate was observed because of their bonding properties to other particles.

\subsection{Effects of polysaccharides and proteins on membrane performance}

The biofilter pretreated surface water contained more polysaccharides and proteins than the raw water (Fig. 7), which indicates that the captured suspended solids inside the biofilter were biodegraded due to the microbial activities inside the media and more polysaccharides and proteins were produced. The average concentration of polysaccharides in the foulants on the membrane surfaces in reactor R1 was 4 times higher than that in the bulk phase. Furthermore, the polysaccharide concentration in the raw water was less than $2.0 \mathrm{mg} / \mathrm{L}$.

During the filtration period, $\sim 410 \mathrm{mg} / \mathrm{L}$ of polysaccharides entered into the reactor $\mathrm{R} 1$ and $\sim 7 \%$ of those polysaccharides were present inside this reactor and in the foulants of membrane surfaces on the last membrane cleaning day. This indicates that $\sim 93 \%$ of the polysaccharides were biodegraded. However, the presence of PAC in other reactors (R2-R5) enhanced this degradation further by up to $97 \%$. This degradation of polysaccharides was not affected by the HRT. Polysaccharide is responsible for the evolution of irreversible fouling (Kimura et al., 2004). The reactors operated at lower HRT (reactors R3 and R5) suffered from the irreversible fouling effects, which indicate that polysaccharide did not cause any significant effects on the irreversible fouling in this submerged PAC-MF MBR once a major portion of them were biodegraded.

In our previous study (Khan et al., 2011), we observed that the bacterial concentration was 2-4 times higher in the reactors with PAC than those without PAC and most of bacteria were attached to PAC and other particles. Similarly, in this study the higher number of bacteria attached to PAC and other particles inside the reactors R2-R5 was probably responsible for higher biodegradation rate of polysaccharides

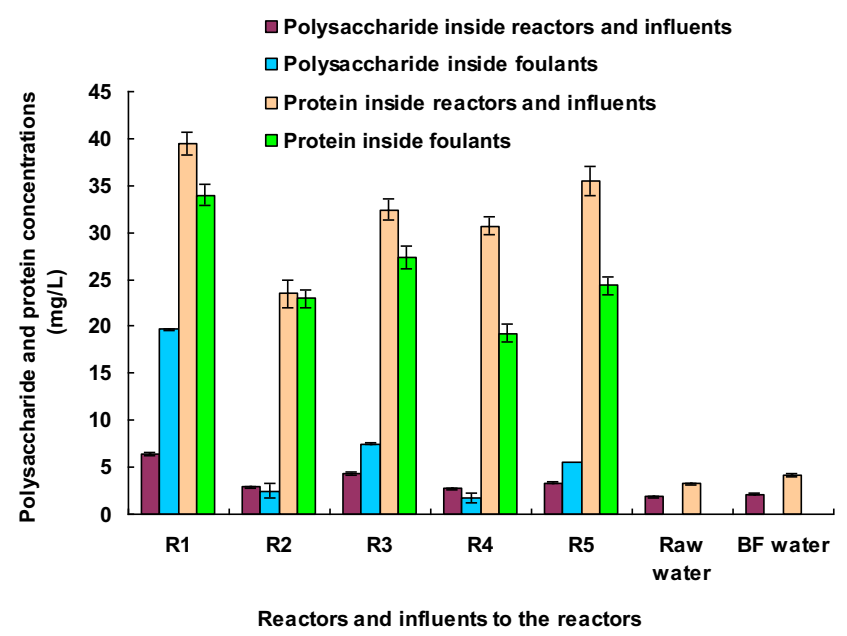

Fig. 7 - Concentrations of polysaccharides and total protein in the influents to the reactors and in the foulants on the MF membrane surfaces on the last membrane cleaning day (Day-45 for R1, R4 and R5 and Day-42 for R2 and R3). Error bars show the \pm standard error of the mean (SEM) was determined in triplicate. The membranes inside R1, R3 and R5 fouled 4 times; however, those inside R2 and R4 fouled thrice and twice, respectively. 
in these reactors than that inside the reactor $\mathrm{R} 1$. Both reactors $\mathrm{R} 4$ and R5 received biofiltered water and operated with PAC; however, polysaccharide concentration in the foulants on the membrane surfaces inside reactor R5, which was operated at lower HRT, was almost twice more than that inside reactor R4, which was operated at higher HRT. Therefore, HRT played a significant role in the accumulation of polysaccharide in the foulants. A similar trend was observed in the case of R2 and R3.

Proteins in the bulk fluid of the reactors accumulated relatively steadily, starting at a low initial value. During the 45 days operational period, $\sim 730 \mathrm{mg} / \mathrm{L}$ of protein from raw water and $\sim 952 \mathrm{mg} / \mathrm{L}$ of protein from biofiltered water entered into the respective reactors. Biofiltered water had more protein than raw water, which indicates that biodegradation of different compounds and SS took place inside this biofilter and more protein was produced by this system.

The influents to the reactors carried low concentration of protein, but inside the reactors and in the foulants of all membrane modules, the amount of total protein was 5-10 times higher. This suggests that microbial degradation and consecutive accumulation of proteins from the source waters resulted in substantial loading of protein to the membrane reactors. The amounts of protein degraded and/or utilized by the microorganisms inside reactors R1-R3 were 89\%, 93\% and $91 \%$, respectively and those inside reactors $\mathrm{R} 4$ and $\mathrm{R} 5$ were $95 \%$ and $94.5 \%$, respectively. Reactors $\mathrm{R} 1-\mathrm{R} 3$ received raw water and with the exception of R1, the other two reactors contained PAC. The PAC adsorbs higher numbers of bacteria (Khan et al., 2011); therefore, enhanced biodegradation is likely to have taken place in reactors R2 and R3. Moreover, reactor R3 was operated at lower HRT and had slightly lower protein degradation. Even though biofiltered water had higher concentration of protein, reactors R4 and R5 showed more protein degradation than other reactors that were fed raw water. The HRT of reactors R4 and R5 was different, but they both degraded protein at the same level. Based on the above discussion, it is clear that the effect of protein level on membrane fouling rate was more prominent in the PAC-MF hybrid MBR; however, the presence of PAC enhanced the degradation of both proteins and polysaccharides. In both cases, HRT did not play a major role in their biodegradation.

Furthermore, a higher proteins/polysaccharides (PN/PS) ratio indicates a higher level of hydrophobicity of EPS (Lee et al., 2003; Sponza, 2003; Sun et al., 2008). The PN/PS ratio of the raw and biofiltered water was 1.8 and 1.9, respectively; however, this ratio increased from 2 to 5 fold for the samples inside the reactors and for the membrane foulants. The affinity between proteins and foulants should generally be greater than that between polysaccharides and flocs in relation to their hydrophobicity and surface charge (Renard et al., 2002). Therefore, a greater amount of protein was found inside the reactors and foulants.

\section{Conclusions}

PAC-MF MBR hybrid systems are becoming one of the most sustainable technologies for drinking water treatment because of the increased stringency of water quality standards, increasingly restricted water sources and supplies, and their more competitive cost.

A robust and new method of EPS extraction from the membrane biofoulant samples was developed. The effect of HRT in the presence and absence of PAC and biofilter pretreatment of surface water on the MF membrane performance, and kinetics of adsorption and biodegradation of EPS components and their effects on MF membrane fouling at different operational conditions of PAC-MF MBR were quantified in this study. The following conclusions can be drawn:

(1) The presence of PAC inside the MF MBR system improved filtration performance and lowered the impact of organic carbon, carbohydrates, polysaccharides and proteins on membrane fouling.

(2) The decrease of HRT increased the frequency of membrane cleaning and irreversible fouling effects on the membranes even though the aeration rate was doubled. Aeration significantly contributed to the removal of cake fouling in this system.

(3) Biofiltration lessens fouling considerably, more than the addition of PAC alone. The organic matter sloughed from the biofiltration unit potentially increased the organic carbon concentration in its effluent. TOC removal efficiency is dependent on the presence of PAC and this efficiency was not affected by the HRT and type of source water. Moreover, the decrease of HRT enhanced the accumulation of carbohydrates and potentially contributed to more fouling of the membrane module. PAC is not a potential adsorbent for carbohydrate. Once the PAC and other particles were attached on the membrane surface forming foulant layers, higher level of carbohydrate was observed because of their bonding properties to other particles.

(4) Major portions of the polysaccharides were biodegraded inside the MBR. Protein effects on membrane fouling rate were more prominent than polysaccharides; however, the presence of PAC enhanced the biodegradation of both proteins and polysaccharides. In both cases, HRT did not play a major role in their biodegradation. Polysaccharide did not cause any significant effects on the irreversible fouling in this submerged PAC-MF MBR once a major portion of them were biodegraded. The biodegradation of EPS components was not equal inside the reactors, which could be due to the presence of different types of microorganisms responsible for biodegradation of the target components. The HRT is one of the most important parameters during system (PAC-MF MBR) design.

The MF systems with PAC could be operated longer than the study period, and the frequency of PAC replacement in the system would depend on the concentrations of the target materials in the PAC-MF MBR effluent and PAC particle sizes.

\section{Acknowledgments}

The authors would like to thank Professor Mark M. Benjamin of the University of Washington for his valuable suggestions 
and comments on this report. This study was supported by the Ministry of Education, Japan.

\section{Appendix A. Supplementary data}

Supplementary data related to this article can be found at http://dx.doi.org/10.1016/j.watres.2012.10.048.

\section{R E F E R E N C E S}

Barker, D.J., Stuckey, D.C., 1999. A review of soluble microbial products (SMP) in wastewater treatment systems. Water Res. 33, 3063-3082.

Barker, D.J., Salvi, S.M.L., Langenhoff, A.A.M., Stuckey, D.C., 2000 Soluble microbial products in ABR treating low-strength wastewater. J. Environ. Eng. 126, 239-249.

Basar, C.A., Karagunduz, A., Cakici, A., Keskinler, B., 2004. Removal of surfactants by powdered activated carbon and microfiltration. Water Res. 38, 2117-2124.

Chen, V.J., Ma, P.X., 2004. Nano-fibrous poly(L-lactic acid) scaffolds with interconnected spherical macropores. Biomaterials 25, 2065-2073.

Chu, H.P., Li, X.Y., 2005. Membrane fouling in a membrane bioreactor (MBR): sludge cake formation and fouling characteristics. Biotechnol. Bioeng. 90, 323-331.

da Nóbrega, R.B., Rocha, B.A.M., Gadelha, C.A.A., SantiGadelha, T., Pires, A.F., Assreuy, A.M.S., Nascimento, K.S., Nagano, C.S., Sampaio, A.H., Cavada, B.S., Delatorre, P., 2012. Structure of Dioclea virgata lectin: relations between carbohydrate binding site and nitric oxide production. Biochimie 94, 900-906.

Doumèche, B., Galas, L., Vaudry, H., Martino, P.D., 2007. Membrane foulants characterization in a drinking water production unit. Food Bioproducts Process. 85, 42-48.

Fabris, R., Lee, E.K., Chow, C.W.K., Chen, V., Drikas, M., 2007. Pretreatments to reduce fouling of low pressure micro-filtration (MF) membranes. J. Memb. Sci. 289, 231-240.

Flemming, H.C., 1993. Mechanistic aspects of reverse osmosis membrane biofouling and prevention, pp. 163-209. In: Amjad, Z. (Ed.), Water Chemistry, and Industrial Applications. Van Nostrand Reinhold, New York.

Fonseca, A.C., Summers, R.S., Greenberg, A.R., Hernandez, M.T., 2007. Extra-cellular polysaccharides, soluble microbial products, and natural organic matter impact on nanofiltration membranes flux decline. Environ. Sci. Technol. 41, 2491-2497.

Goldstein, I.J., Hughes, R.C., Monsigny, M., Osawa, T., Sharon, N., 1980. What should be called a lectin. Nature 285, 66.

Gómez-Suárez, C., Pasma, J., van der Borden, A.J., Wingender, J., Flemming, H.-C., Busscher, H.J., van der Mei, H.C., 2002. Influence of extracellular polymeric substances on deposition and redeposition of Pseudomonas aeruginosa to surfaces. Microbiology 148, 1161-1169.

Huang, Z., Ong, S.L., Ng, H.Y., 2011. Submerged anaerobic membrane bioreactor for low-strength wastewater treatment: effect of HRT and SRT on treatment performance and membrane fouling. Water Res. 45, 705-713.

Jang, N., Ren, X., Kim, G., Ahn, C., Cho, J., Kim, I.S., 2007. Characteristics of soluble microbial products and extracellular polymeric substances in the membrane bioreactor for water reuse. Desalination 202, 90-98.

Jarusutthirak, C., Amy, G., 2006. Role of soluble microbial products (SMP) in membrane fouling and flux decline. Environ. Sci. Technol. 40, 969-974.
Jia, Y., Wang, R., Fane, A.G., 2009. Hybrid PAC-submerged membrane system for trace organics removal II. System simulation and application study. Chem. Eng. J. 149, 42-49.

Khan, M.M.T., Ohgaki, S., Takizawa, S., Katayama, H., 2001. Development of powdered activated carbon and microfiltration membrane system for water treatment. J. Jpn. Soc. Civil Eng. 8, 369-372.

Khan, M.M.T., Lewandowski, Z., Takizawa, S., Yamada, K., Katayama, H., Yamamoto, K., Ohgaki, S., 2009. Continuous and efficient removal of THMs from river water using MF membrane combined with high dose of PAC. Desalination 249, 713-720.

Khan, M.M.T., Stewart, P.S., Moll, D.J., Mickols, W.E., Burr, M.D., Nelson, S.E., Camper, A.K., 2010. Assessing biofouling on polyamide reverse osmosis (RO) membrane surfaces in a laboratory system. J. Memb. Sci. 349, 429-437.

Khan, M.M.T., Takizawa, S., Lewandowski, Z., Jones, W.L., Camper, A.K., Katayama, H., Kurisu, F., Ohgaki, S., 2011. Membrane fouling due to dynamic particle size changes in the aerated hybrid PAC-MF system. J. Memb. Sci. 371, 99-107.

Kim, H.S., Katayama, H., Takizawa, S., Ohgaki, S., 2005. Development of a microfilter separation system coupled with a high dose of powdered activated carbon for advanced water treatment. Desalination 186, 215-226.

Kim, H.S., Takizawa, S., Ohgaki, S., 2006. Application of microfiltration systems coupled with powdered activated carbon to river water treatment. Desalination 202, 271-277.

Kimura, K., Hane, Y., Watanabe, Y., Amy, G., Ohkuma, N., 2004. Irreversible membrane fouling during ultrafiltration of surface water. Water Res. 38, 3431-3441.

Kocourek, J., Horejsí, V., 1981. Defining a lectin. Nature 290, 188.

Lam, S.K., Ng, T.B., 2011. Lectins: production and practical applications. Appl. Microbiol. Biotechnol. 89, 45-55.

Lebeau, T., Lelievre, C., Buisson, H., Cleret, D., Van de Venter, L.W., Cote, P., 1998. Immersed membrane filtration for the production of drinking water: combination with PAC for NOM and SOCs removal. Desalination 117, 219-231.

Lee, J., Ahn, W.J., Lee, C.H., 2001. Comparison of the filtration characteristics between attached and suspended growth microorganisms in submerged membrane bioreactor. Water Res. 35, 2435-2445.

Lee, W., Kang, S., Shin, H., 2003. Sludge characteristics and their contribution to micro-filtration in submerged membrane bioreactors. J. Memb. Sci. 216, 217-227.

Lee, S., Lee, J.W., Kim, S., Park, P.K., Kim, J.H., Lee, C.H., 2009. Removal of $17 \beta$-estradiol by powdered activated carbonmicrofiltration hybrid process: the effect of PAC deposition on membrane surface. J. Memb. Sci. 326, 84-91.

Meng, F., Shi, B., Yang, F., Zhang, H., 2007. Effect of hydraulic retention time on membrane fouling and biomass characteristics in submerged membrane bioreactors. Bioprocess Biosyst. Eng. 30, 359-367.

Mikkelsen, L.H., Keiding, K., 2002. Physico-chemical characteristics of full scale sewage sludges with implications to dewatering. Water Res. 36, 2451-2462.

Nagaoka, H., Kono, S., Yamanishi, S., Miya, A., 2000. Influence of organic loading on membrane fouling in membrane separation activated sludge process. Water Sci. Technol. 41, 355-362.

Ng, C.A., Sun, D., Fane, A.G., 2006. Operation of membrane bioreactor with powdered activated carbon addition. Separ. Sci. Technol. 41, 1447-1466.

Oh, H.K., Takizawa, S., Ohgaki, S., Katayama, H., Oguma, K., Yu, M.J., 2007. Removal of organics and viruses using hybrid ceramic MF system without draining PAC. Desalination 202, 191-198.

Park, N., Kwon, B., Kim, I.S., Cho, J., 2005. Biofouling potential of various NF membranes with respect to bacteria and their 
soluble microbial products (SMP): characterizations, flux decline, and transport parameters. J. Memb. Sci. 258, 43-54.

Renard, D., Lavenant, L., Sanchez, C., Hemar, Y., Horne, D., 2002. Heat-induced flocculation of microparticulated whey proteins (MWP); consequences for mixed gels made of MWP and $\beta$ lactoglobulin. Colloid. Surf. B Biointerface 24, 73-85.

Sponza, D.T., 2003. Investigation of extracellular polymeric substances (EPS) and physicochemical properties of different activated sludge flocs under steady-state conditions. Enzyme Microb. Technol. 32, 375-385.

Sun, F.-Y., Wang, X.-M., Li, X.-Y., 2008. Visualisation and characterisation of biopolymer clusters in a submerged membrane bioreactor. J. Memb. Sci. 325, 691-697.

Tansel, B., Sager, J., Garland, J., Xu, S., Levine, L., Bisbee, P., 2006. Deposition of extracellular polymeric substances (EPS) and microtopographical changes on membrane surfaces during intermittent filtration conditions. J. Memb. Sci. 285, 225-231.

Thiruvenkatachari, R., Shim, W.G., Lee, J.W., Aim, R.B., Moon, H., 2006. A novel method of powdered activated carbon (PAC) precoated microfiltration (MF) hollow fiber hybrid membrane for domestic wastewater treatment. Colloid. Surf. A Physicochem. Eng. Aspect. 274, 24-33.

Tsuneda, S., Aikawa, H., Hayashi, H., Yuasa, A., Hirata, A., 2003. Extracellular polymeric substances responsible for bacterial adhesion onto solid surface. FEMS Microbiol. Lett. 223, 287-292.
Turakhia, M.H., Characklis, W.G., 1989. Activity of Pseudomonas aeruginosa in biofilms: effect of calcium. Biotechnol. Bioeng. 33, 406-414.

Ueda, T., Hata, K., Kikuoka, Y., Seino, O., 1997. Effects of aeration on suction pressure in a submerged membrane bioreactor. Water Res. 31, 489-494.

Vigneswaran, S., Guo, W.S., Smith, P., Ngo, H.H., 2006. Submerged membrane adsorption hybrid system (SMAHS): process control and optimization of operating parameters. Desalination 202, 392-399.

Wingender, J., Neu, T.R., Flemming, H.-C., 1999. What are bacterial extracellular polymeric substances?, pp. 1-19 In: Wingender, J., Neu, T.R., Flemming, H.-C. (Eds.), Microbial Extracellular Polymeric Substances. Springer, New York.

Wotton, R., 2004. The ubiquity and many roles of exopolymers (EPS) in aquatic systems. Scientia Marina 68 (Suppl. 1), 13-21.

Yang, W., Paetkau, M., Cicek, N., 2010. Effects of powdered activated carbon dosing on sludge characteristics and estrogen removal in membrane bioreactors. Water Sci. Technol. 61, 2193-2198.

Ye, Y., Le Clech, P., Chen, V., Fane, A.G., 2005. Evolution of fouling during crossflow filtration of model EPS solutions. J. Memb. Sci. 264, 190-199.

Zhang, X., Bishop, P.L., Kinkle, B.K., 1999. Comparison of extraction methods for quantifying extracellular polymers in biofilms. Water Sci. Technol. 39, 211-218. 